\title{
Assessing the effect of autonomous driving on value of travel time savings: a comparison between current and future preferences
}

\author{
Viktoriya Kolarovab", Felix Steck ${ }^{\mathrm{a}}$, Francisco J. Bahamonde-Birke ${ }^{\text {acd }}$ \\ ${ }^{a}$ German Aerospace Center, Institute of Transport Research, Rutherfordstr. 2, 12489 Berlin, Germany \\ ${ }^{b}$ Humboldt-Universität zu Berlin, Georaphy Department, Rudower Chaussee 16, 12489 Berlin, Germany \\ ${ }^{c}$ Technische Universität Berlin, Straße des 17. Juni 135, 10623 Berlin, Germany \\ ${ }^{d}$ Universiteit Utrecht, Vening Meineszgebouw A, Princetonlaan 8a, 3584 CB Utrecht, Netherlands
}

Cite as: Kolarova, V., Steck, F., Bahamonde-Birke, F. (2019) Assessing the effect of autonomous driving on value of travel time savings: a comparision between current and future preferences. Transport Research Part A: Policy and Practice. Vol.129, 155-169.

\begin{abstract}
Due to digitalization trends and rapid technological development, cars are becoming more technologically advanced with an on-going trend towards fully automated vehicles. Understanding possible changes in user preferences and the impact on mobility of autonomous driving is of great importance for policy and transport planning authorities in light of urbanization trends, demographic change, and environmental challenges. Despite the relevance of the topic, there are limited empirical insights on user preferences, once autonomous driving becomes available. To close this gap and analyze the potential changes in the value of travel time savings (VTTS) resulting from the availability of autonomous driving, an online survey using revealed and stated preference methods was conducted. In the survey user preferences toward currently available and future available modes of transportation were assessed using two discrete choice experiments. VTTS calculations are based on an estimated joint mixed logit model. The results of the study show an average VTTS reduction of $41 \%$ for autonomous driving compared to driving a conventional car, however, only for commuting trips. For leisure or shopping trips, no significant changes in the VTTS were found. Considering shared autonomous vehicles (SAV), the results indicate that using SAV is perceived as a less attractive option than using a privately owned autonomous vehicle. Translating the results into policy implications, a potential conflict between individual benefits of autonomous driving and societal goals is identified. Finally, policy recommendations are discussed.
\end{abstract}

Keywords: autonomous vehicles, shared autonomous vehicles, value of travel time savings, discrete choice experiment, mixed logit

\footnotetext{
* Corresponding author:

Viktoriya Kolarova

E-mail: viktoriya.kolarova@dlr.de
} 


\section{Introduction}

In recent decades, the trends towards digitalisation and rapid developments in technology have led to ever-increasing automation in all areas of daily life. As a result, road vehicles, too, are becoming more technologically advanced in their automation and connectivity and there is a continuing trend towards fully autonomous vehicles (Fagnant and Kockelman, 2015). In terms of automated driving functions, vehicles can be classified into five levels - ranging from driver assistance and partial automation (level 1 and 2), through conditional automation (level 3) and high automation (level 4) to full automation (level 5), in other words potentially driverless (SAE, 2014). The highest level of automation (level 5) can enable new mobility services (Lenz and Fraedrich, 2016), such as shared autonomous vehicles (SAVs). These vehicles are not privately owned by a single person, but provided by a company. They can be then used on demand - either as individual autonomous car-sharing services, similar to current taxi services, or as an autonomous ride-sharing service, where people with destinations near each other can share the ride, having the advantage of lower cost per kilometre travel, although with somewhat higher waiting times than those associated with autonomous car-sharing services (Kröger and Kickhöfer, 2017). Both kinds of services could complement traditional public transport (e.g. solving the first-/last-mile problem), or even, where it is deficient today, act as a substitute (Yap et al., 2016, Mosquet et al., 2015, Ohnemus and Perl, 2016). From a user perspective, these services could allow true door-to-door trips for individuals not having access to a car today (Burns et al., 2013).

There are high expectations placed on autonomous driving, amongst which are: a higher level of safety on the roads; reduced congestion; provision of individual mobility to people currently not allowed or not able to drive; and enabling people who use a car to undertake other activities, while also travelling in a more comfortable way (Trommer et al., 2016, Anderson et al., 2014, Litman, 2014). At the same time, as travel time can be spent in a more pleasurable or more productive way, using a car might become more attractive. Moreover, considering a use case where autonomous vehicles (AVs) make up part of a car-sharing fleet, the use of individual mobility options might become attractive for an even broader group of users who cannot - or do not wish to - own a private vehicle. Consequently, if using a motor vehicle becomes more attractive and, additionally, available to a broader user group, the result will be more vehicles on the road and more vehicle-kilometres travelled (Trommer et al., 2016, Gucwa, 2014, Childress et al., 2014, Harper et al., 2016). Thus, despite the potential benefits of autonomous driving, there is also a risk of causing additional traffic and hence adding to, rather than resolving, transport-related challenges.

In summary, it is expected that autonomous driving may significantly change travel behaviour and mode choice, potentially transforming our understanding of mobility in a way that is hard to predict at this point. At the same time, understanding user preferences, once autonomous driving is available, becomes increasingly relevant in the light of urbanisation trends, demographic change, and environmental challenges. Even though vehicles with level 5 automation will potentially enter the market no sooner than 2027 (ERTRAC, 2015, Dokic et al., 2015, PWC, 2015) and it might take decades for the technology to reach a substantial penetration rate (Trommer et al., 2018, Nieuwenhuijsen et al., 2018, Litman, 2018), anticipating its future impact on mobility is crucial for developing a desirable transition pathway of the technology. Along these lines, offering early insights into the potential impact of automation on user preferences is of great importance for policy and transport planning authorities. Those insights are crucial to design strategies and in evaluating future possible scenarios, in order to integrate AVs into transport systems in a way that allows for their full potential to unfold, while preventing, or at least mitigating, potential negative developments.

The examination of mode choice preferences in theoretical and empirical studies in transport usually centres around estimating the value of travel-time savings (VTTS). The concept of VTTS reflects the reality, derived from microeconomic theory, that people take transport decisions in the context of a constrained time budget - this constraint determines how people choose whether they spend their time on one activity or on another, and how much they would pay to avoid having to spend time on a particular activity (Hensher, 2011). The subjective VTTS is therefore defined as the willingness to pay for one unit of travel time saving (Jara-Diaz, 2000). In the context of autonomous driving, it is 
reasonable to assume that the perception of time spent in a vehicle might change (from present-day values) in a positive way - that is, the VTTS for autonomous driving might decrease (i.e. the disutility of travel time become less negative). This is because people can spend their time in a more pleasurable or productive way; and, moreover, the stress level in tiresome traffic situations, such as congestion or monotonous routine commuting trips, might reduce when riding autonomously (Becker and Axhausen, 2016). There thus arises the question, when considering the impact of these changes on travel behaviour and mode choice: what variation in the VTTS can be expected, once autonomous driving is available? Furthermore, estimating the VTTS for new mobility options, such as SAVs, becomes ever more relevant when forecasting mode choice decisions.

There is a large body of theoretical and empirical literature dedicated to the estimation of the VTTS for the currently available modes of transport as national studies on mode choices and the role of VTTS (e.g., Axhausen et al., 2015, Arup, ITS Leeds and Accent, 2015) are an important base for transport infrastructure and policy planning. Results from previous studies on VTTS show that the values differ between modes of transport, according to trip purposes, and depending on the trip distance; they are also affected by specific characteristics of the route, such as the level of congestion or the need to change mode or vehicle en route (Abrantes and Wardman, 2011, Shires and de Jong, 2009). For instance, the VTTS for commuting trips is found to be higher than that for leisure or shopping trips, and driving in congestion is associated with a higher VTTS than driving in a freeflowing traffic (Abrantes and Wardman, 2011). Also, car passengers are found to have a lower VTTS than car drivers (Mackie et al., 2003). Therefore, when considering how automation might affect VTTSs, we can expect that there will be a reduction in the VTTS since users travel as passengers in a way that is similar to using taxis or taking public transport (although in fact AVs will exhibit substantial advantages over these alternatives, in terms of privacy afforded and the range of activities that can be performed en route, especially if the internal configuration of the vehicle can be personalised). However, empirical data is required to validate this assumption, and to find out how riding autonomously in a privately owned car differs from riding in an SAV.

While the VTTS for current existing modes of transport can be estimated by relying upon revealed or stated preference (SP) methods, seeking to establish the VTTS for novel (as yet unavailable) mobility options, such as autonomous driving, is possible only using SP approaches or plausible assumptions. While relying on plausible assumptions and sensitivity analysis on the basis of simulation models might provide significant insight into the possible impacts of automation, empirical research is still required in order to address the users' perspective and to validate/provide data input for travel behavioural models upon which the simulation tools are based. Along these lines, there are early simulation studies which report that a reduction in the VTTS through automation might potentially lead to an increase in travel demand and in car mode share (Gucwa, 2014, Childress et al., 2014, Kröger et al., 2016, Wadud et al., 2016, Correia and van Arem, 2016), but they simply rely upon assumption to quantify the extent to which the VTTS will be affected by automation. While the technique of SP suffers from shortcomings when used to address new, for the respondents unfamiliar, alternatives, it still can help gaining empirical insights about potential user preferences regarding autonomous driving. Acknowledging the limitations of SP, using them and interpreting their results with care, can be a suitable tool to consider the user perspective on the new technology.

Early empirical works have addressed the VTTS for autonomous driving by relying on the SP approach (Yap et al., 2016, Winter et al., 2017, Krueger et al., 2016, Steck et al., 2018, de Looff et al., 2018). The focus of most of them is user preferences regarding different types of SAV, owing to the higher level of uncertainty about the impact of these new mobility options compared to privately owned AVs. The results broadly indicate differences between early and late adopters of these services (Winter et al., 2017), as well as showing that using an SAV alone and sharing the journey are perceived as two distinct mobility options (Krueger et al., 2016). These differences might be partly related to psychological barriers associated with sharing a ride with strangers as such acceptance issues were found in early studies on carpooling service (e.g., Correia and Viegas, 2011). Considering a privately owned AV, there is early empirical evidence for a reduction of the VTTS for commuting 
trips (Steck et al., 2018) and for an AV with an office interior compared to a an AV with a leisure one (de Looff et al., 2018, Correia et al., 2019). The results from the latter study confirm also a theoretical reduction in VTTS for work vehicle derived by the authors from the existing microeconomics theory on perceived VTTS (see Correia et al., 2019). Simultaneously, a rather higher VTTS was found for the use of AVs as a first-/last-mile solution, suggesting concerns in attitude towards and perception of the technology (Yap et al., 2016). However, these studies focus mainly on specific use cases of autonomous driving and the characteristics of the trips that AVs are used for (first-/last-mile, car- or ride-sharing, commuting, etc.). Moreover, in most cases only motorised modes of transport have been considered, and a baseline can only be a comparison with existing values from the literature, as the studies focus only on user preferences when future mobility options are available. An exception here is the study from Correia et al. (2019), where the same experiment was conducted with a different sample presenting a chauffeur-driven vehicle instead of an AV. At the same time, we suggest that assessing preferences regarding currently available modes of transport of the same sample can be a more accurate base line. This is because changes in the preferences can be directly addressed avoiding additional error sources, such as differences in the samples or in the methodology used.

The aim of this study is to contribute to the field by closing these research gaps by providing empirical evidence on how autonomous driving might change the VTTS and choice of mode. The study addresses both privately owned AVs and SAVs. Moreover, while the SP approach provides powerful insights into the aforementioned new use cases, the lack of familiarity of the population with these options might affect the accuracy of their responses. Therefore, we have focused our analysis on higher-level features, such as that of the VTTS. Along these lines, and in order to have a better depiction of the situation regarding available choices, we contrast current preferences (also based on SP, but considering currently available mobility options) with potential choices when AVs become available. The results of the study can potentially constitute an important building block in the planning of future strategic policy steps for the implementation of autonomous driving into existing transport systems.

\section{Study design and data set}

To address the value of travel-time savings (VTTS) for autonomous driving, an online survey was conducted in 2017. The respondents were contacted by a professional service provider using an online panel, and the sample, consisting of 511 respondents, was drawn to represent the age and gender distribution in the German population of the age group between 18 and 69 years old. After removing incomplete/implausible records, and non-trading, lexicographic and inconsistent response patterns, as well as response of an implausible duration, the final sample consisted of 485 individual records of adequate quality for inclusion. To assess the VTTS for autonomous driving, a combination of revealed and stated preference (SP) methods was applied following a pivot design, i.e. a discrete-choice experiment with the attributes of the alternatives pivoted around a given value, as proposed by Hensher and Greene (2002). Additionally, the survey includes questions on individual travel patterns, socioeconomic data, and willingness to use and pay for autonomous driving functions.

In the revealed preference part of the survey, the respondents were asked to report details of their regular commuting, leisure or shopping trips. The reported trips were used as reference trips for creating individual decision situations in the SP part of the survey by reducing or increasing the trip time and cost of each alternative around a computed base level. The base level for the mode of transport which is currently used by the respondents was computed using the reported trip duration. The individual base levels for all other alternatives were estimated using the reported trip length and additional data from the literature (see notes in Table 1). The SP part consisted of two discrete-choice experiments. In the first choice experiment, the respondents had to choose between currently available modes of transport for their reported trip, including walk, bicycle, privately owned car and public transport. The second discrete-choice experiment additionally included mobility options available in the future: two autonomous driving concepts to replace a privately owned conventional car - a privately owned vehicle with automation capability, and a shared autonomous vehicle (SAV), i.e. an autonomous vehicle (AV) that can be used on demand. As the SAV combines characteristics of taxi 
and car-sharing concepts, we named this mobility option 'driverless taxi' in the survey and in the video used for introducing the concept in order to provide a ready understanding of its characteristics to the participants. This was done because we assumed that a significant part of the general population is not familiar with on-demand or shared vehicle services (both as a term and as a service) and that a taxi service is the one closest to the concept that we looked at. In this paper we will, however, refer to this alternative using the term 'SAV'.

The two autonomous driving concepts were presented to the participant by means of two short animated videos before the second choice experiment. Acknowledging that the responses regarding autonomous driving are highly affected by the way the concept is presented, we used the videos instead of only providing text description, presented how a trip with an AV might looks like instead of showing only information about such vehicles, and described the usage of AVs in as neutral a way as possible avoiding evaluative adjectives. An autonomous vehicle was described as "a road vehicle which can perform the driving task, i.e., can brake, steer and accelerate by itself. The driver doesn't have to pay attention to the traffic or to take care of the driving task and can use the travel time for other activities (such as reading, watching movies, surfing in internet)." In the videos, the main character, Mrs Schmidt, uses her privately owned AV or an SAV to reach her destination. Both vehicles are shown picking her up from her location and dropping her off at a given destination. Hence, there is no access and egress time, but she need to wait for the vehicle. In the privately owned AV, Mrs. Schmidt could choose whether she wants to drive manually or ride autonomously. This description of the vehicle's capabilities allows us to avoid confronting the respondents with two different vehicle types in the choice sets (a conventional vehicle and an AV), as this would make the choice situation more complicated and would require an early purchase decision about an AV. Consequentially, if a respondent chooses to use an AV for the trip, then he/she could decide whether riding autonomously or driving manually (i.e., using the AV as a conventional car). An additional question after the choice experiments addresses the preferences of each of the respondents regarding riding autonomously or driving manually. We used this question in model estimation to distinguish between the perceptions of the time spent in an AV riding autonomously and in an AV driving manually (i.e., using an AV as a conventional car). Confronting respondents with a privately owned car able to drive autonomously allows for assessing willingness to use the function and its impact on the time evaluation instead of assessing car purchase, which is a more complex decision process. Simultaneously, given that the first choice experiment included a conventional car in the choice-set, this experiment is used as a control groups and allows validating the results on preferences toward use of a privately owned car. In contrast to the privately owned car (i.e., the privately owned AV), the SAV was presented as a vehicle which has no steering wheel or brakes, and so could not be driven manually. A ride with an SAV could additionally be shared with other passengers who have similar origin and destination with the advantage of lower cost for the service users. This, however, was only described in a short text and was not shown in the video as it was only an additionally considered aspect and not the main scope of the study. Selected scenes from the videos are presented in the appendix.

Each of the two discrete-choice experiments consisted of eight choice situations. The attributes, along with the attribute levels used in the experiments are summarised in Table 1. Since we aimed to assess the individual trade-offs between time and cost, we considered the travel, access/egress and waiting times as well as the cost of the different alternatives. In order to confront the respondents with realistic alternatives, we used a pivot design based on the reported trip length and duration combined with additional information on the average speeds and costs of each transport mode in Germany to create the characteristics of the alternatives. The range of reduction and increase around the computed values follow the variation used in the national survey on VTTS for Germany conducted by Axhausen et al. (2015). The SAV had an additional attribute showing whether the respondent will use the vehicle alone, or will have to share the vehicle with other passengers. When sharing a ride, the cost per kilometre was reduced proportionally. In this way, the concept of comparing car-sharing with ridesharing could be approached without introducing an additional mobility option into the choice set. 
Table 1. Attributes and their levels

\begin{tabular}{|c|c|c|c|}
\hline $\begin{array}{l}\text { Mode of } \\
\text { transport }\end{array}$ & Walk & Bike & Public transport \\
\hline \multirow[t]{4}{*}{$\begin{array}{l}\text { Attribute: } \\
\text { Attribute } \\
\text { levels }\end{array}$} & $\begin{array}{l}\text { Time: }-30 \%|-10 \%|+20 \% \\
\text { of the reported trip time } \\
\text { (Speed: } 4.9 \mathrm{~km} / \mathrm{h} \text { ) }\end{array}$ & $\begin{array}{l}\text { Time: }-30 \%|-10 \%|+20 \% \text { of } \\
\text { the reported trip time (Speed: } \\
15 \mathrm{~km} / \mathrm{h} \text { ) }\end{array}$ & $\begin{array}{l}\text { In-vehicle time: }-30 \%|-10 \%| \\
+20 \% \text { of the reported trip time } \\
\text { (Speed: } 18-51 \mathrm{~km} / \mathrm{h} *)\end{array}$ \\
\hline & & & Access/egress time: $2|5| 10 \mathrm{~min}$ \\
\hline & & & Waiting time: $2|5| 10 \mathrm{~min}$ \\
\hline & & & $\begin{array}{l}\text { Costs: }-30 \%|-10 \%|+20 \% \text { of } \\
\text { estimated cost for the trip }(1.5-6 \\
\text { Euro*) }\end{array}$ \\
\hline $\begin{array}{l}\text { Mode of } \\
\text { transport }\end{array}$ & $\begin{array}{l}\text { Conventional car } \\
\text { (only in the first experiment) }\end{array}$ & $\begin{array}{l}\text { Autonomous vehicle } \\
\text { (only in the second choice } \\
\text { experiment) }\end{array}$ & $\begin{array}{l}\text { Shared autonomous vehicle } \\
\text { (only in the second choice } \\
\text { experiment) }\end{array}$ \\
\hline \multirow{6}{*}{$\begin{array}{l}\text { Attribute: } \\
\text { Attribute } \\
\text { levels }\end{array}$} & In-vehicle time: $-30 \%$ & In-vehicle time: $-30 \%|-10 \%|$ & In-vehicle time: $-30 \%|-10 \%|$ \\
\hline & $\begin{array}{l}-10 \% \mid+20 \% \text { of the reported } \\
\text { trip time (Speed: } 26- \\
\left.68 \mathrm{~km} / \mathrm{h}^{*}\right)\end{array}$ & $\begin{array}{l}+20 \% \text { of the reported trip time } \\
\text { (Speed: } 26-68 \mathrm{~km} / \mathrm{h}^{*} \text { ) }\end{array}$ & $\begin{array}{l}+20 \% \text { of the reported trip time } \\
\text { (Speed: } 26-68 \mathrm{~km} / \mathrm{h}^{*} \text { ) }\end{array}$ \\
\hline & $\begin{array}{l}\text { Access/egress time: } 2|5| \\
10 \mathrm{~min}\end{array}$ & & \\
\hline & & Waiting time: $2|5| 10 \mathrm{~min}$ & Waiting time: $2|5| 10 \mathrm{~min}$ \\
\hline & & & Ride-sharing: no | yes \\
\hline & $\begin{array}{l}\text { Costs: }-30 \%|-10 \%|+20 \% \\
\text { of estimated cost for the trip } \\
(0.20 \text { Euro/min*) }\end{array}$ & $\begin{array}{l}\text { Costs: }-30 \%|-10 \%|+20 \% \text { of } \\
\text { estimated cost for the trip } \\
(0.20 \text { Euro/min* })\end{array}$ & $\begin{array}{l}\text { Costs: }-30 \%|-10 \%|+20 \% \text { of } \\
\text { estimated cost for the trip } \\
(0.20 \text { Euro/min*) }\end{array}$ \\
\hline
\end{tabular}

*distance-dependent estimation

Note: Average speeds per mode of transport were computed using the German National Household Travel Survey, MiD (DLR and infas, 2010); the costs per kilometre for the privately owned car were drawn from ADAC (2017) - only fuel and maintenance costs were included; the price for using a shared autonomous vehicle followed results from current analysis (Kröger and Kickhöfer, 2017); distance-dependent costs for public transport were drawn from existing rates for Germany starting from 1.5 Euro; season, year or student pass/tickets for public transport were not considered

In order to enhance the data quality of the experiments by maximising the information obtained from each choice situation, a Bayesian efficient design was created using the software Ngene (ChoiceMetrics, 2012). The priors, i.e. the parameters for the estimation of the efficient design, were drawn from model estimations using the data collected in a pre-test with 30 participants prior to the field test. Despite the small sample size of the pre-test, the relevant priors were significant and also of the expected range and sign. Following suggestions from the literature, a statistically more efficient design can be generated even when limited information about the parameters is given (Bliemer and Rose, 2005). Moreover, we optimised the design for different trip lengths in order to consider the effect of trip distance on mode choice.

Table 2 provides an overview of the characteristics of the reference trips reported in the revealed preference part of the survey and a comparison of the study sample with the German National household travel survey, Mobilität in Deutschland or MiD 2008 (DLR and infas, 2010). The reference trips refer, as mentioned above, to regular trips made by the participant used as a reference for creating individual decision situations in the SP. The descriptive analysis shows that commuting trips are on average longer than shopping and leisure trips. A comparison of the modal split between trip purposes shows that the privately owned car is the preferred mode of transport across all trip purposes. Leisure and shopping trips are characterised by a higher share of trips made by foot, which can be attributed to the short distances involved. After the privately owned car, public transport is the second most popular mode of transport for commuting trips. When comparing these values with the average characteristics of trips in the German National household travel survey MiD 2008 (DLR and infas, 2010), similar tendencies can be observed in both trip distance statistics and the modal split. Only commuting trips are on average longer in the study sample than in MiD 2008; also, some active modes of transport (bicycle for shopping trips, and walk for leisure trips) are underrepresented and public transport (for commuting and leisure trips) overrepresented in the study sample when compared to MiD 2008. 
Table 2. Overview of the characteristics of the reported reference trips compared to the German National household travel survey MiD 2008 (DLR and infas, 2010)

\begin{tabular}{|c|c|c|c|c|c|c|}
\hline \multirow[t]{2}{*}{ Trip purpose: } & \multicolumn{2}{|c|}{ commuting } & \multicolumn{2}{|c|}{ leisure } & \multicolumn{2}{|c|}{ shopping } \\
\hline & $\begin{array}{c}\text { Study } \\
\text { sample } \\
(\mathrm{n}=172) \\
\end{array}$ & MiD 2008 & $\begin{array}{c}\text { Study } \\
\text { sample } \\
(\mathrm{n}=142)\end{array}$ & MiD 2008 & $\begin{array}{c}\text { Study } \\
\text { sample } \\
(\mathrm{n}=171) \\
\end{array}$ & MiD 2008 \\
\hline \multicolumn{7}{|c|}{ Trip distance statistics [km] } \\
\hline $1^{\text {st }}$ quartile & 5 & 3 & 3 & 1 & 1 & 1 \\
\hline Median & 15 & 9 & 6 & 4 & 3 & 2 \\
\hline $\begin{array}{l}\text { Mean (std. } \\
\text { dev.) }\end{array}$ & $18(17)$ & $14(16)$ & $11(15)$ & $9(13)$ & $5(7)$ & $5(8)$ \\
\hline $3^{\text {rd }}$ quartile & 25 & 19 & 12 & 10 & 6 & 5 \\
\hline \multicolumn{7}{|c|}{ Mode of transport [\%]* } \\
\hline Walk & 9 & 8 & 20 & 32 & 31 & 26 \\
\hline Bicycle & 8 & 11 & 12 & 10 & 4 & 11 \\
\hline $\begin{array}{l}\text { Public } \\
\text { transport }\end{array}$ & 23 & 14 & 13 & 6 & 4 & 3 \\
\hline $\begin{array}{l}\text { Privately } \\
\text { owned car }\end{array}$ & 61 & 67 & 55 & 51 & 61 & 61 \\
\hline
\end{tabular}

Further descriptive analysis was carried out of the distribution of socioeconomic characteristics within the study sample, and then compared to the characteristics of the German population as a whole. The study sample was recruited to be representative by age and gender for Germany. A comparison of the share of individuals belonging to different income classes shows that solely persons with high income were underrepresented in the study sample - this was probably due to the method of sample recruitment, which involved a small payment of 2 Euro as an incentive to take part in the survey.

\section{Theoretical and modelling framework}

The most common approach to address discrete choices in transportation is based on the random utility theory, which postulates that an individual, $n$, assigns a specific utility to every available alternative, $i$, and chooses the one that maximises his/her net personal utility (McFadden, 1974; Ortúzar and Willumsen, 2011). As the modeller does not have information about all elements considered by each individual, the net utility $U_{n, i}$ of the alternative $i$ for the individual $n$ is represented through a measurable deterministic part and a random, i.e. stochastic, component. The deterministic part is a vector of the explanatory variables including the attributes of the alternatives, as well as the socioeconomic characteristics of the individuals. The stochastic component, represented through the error term $\varepsilon_{n, i}$, accounts for all relevant attributes ignored by the modeller. Assuming an additive linearity, the expected utility of the alternative $i$ can therefore be expressed as follows:

$$
U_{n, i}=\beta X_{n, i}+\varepsilon_{n, i}
$$

where $\beta$ is a vector of parameters to be estimated. The assumptions regarding the error term $\varepsilon_{n, i}$, would lead to different model specifications. The most common assumption is that the random residuals are independent and identically distributed (iid) following a Gumbel (also called Extreme Value Type I, or EV1) distribution, which leads to the Multinomial Logit (MNL) model (McFadden, 1974, Ortúzar and Willumsen, 2011). Hence, the MNL does not allow for any consideration of heterogeneity among the respondents, nor can it capture the pseudo-panel nature of the discrete-choice data (i.e. more than one response per respondent). In order to cope with these restrictions inherent in the MNL, it is possible to rely upon a Mixed Logit (ML; Boyd and Mellman, 1980, Cardell and Dunbar, 1980, Train, 2009) specification, which allows relaxing the assumptions that the model parameters are the same for all individuals in the sample, and likewise the assumption that there is no correlation across observations 
from the same respondent (Hensher and Greene, 2002; Revelt and Train, 1998). The utility function of an ML with pseudo-panel data extends equation (1) to the following formulation:

$$
U_{n, i, t}=b X_{n, i, t}+\eta_{n} X_{n, i, t}+\varepsilon_{n, i, t}
$$

In equation (2), the coefficient vector $\beta$ from equation (1) is represented as $\beta_{n}=b+\eta_{n}$, where $b$ is the population mean and the $\eta_{n}$ is a random term following a distribution to be established by the analysis with zero mean and a standard deviation to be estimated. Estimating $b$ as a random parameter allows for analysis of different evaluations of $X_{n, i, t}$ across the respondents. The $t$ represents the choice situations with which a single respondent $n$ is confronted. Therefore, $b+\eta_{n}$ is assumed not to vary across $t$ taking into account that the evaluation of the attributes of the alternatives remains the same across all observations associated with the same respondent. Consequently, in the ML the probability of choosing the alternative $i$ is a weighted mean of the MNL probabilities at a specific $\eta$, weighted over the distribution of $\eta$. In the following formulation, the choice probability $L_{n, i}$ represents the MNL probabilities for a given value of $\eta$ :

$$
P_{n, i}=\int L_{n, i}(\beta) f(\beta \mid \eta) d \beta
$$

Considering that one individual faces $t$ choice situations, the probability of observing a set of individual choices can be expressed as follows:

$$
L_{n, i}(\beta)=\prod_{t=1}^{T}\left(\frac{e^{\beta X_{n, i, t}}}{\sum_{j=1}^{J} e^{\beta X_{n, j, t}}}\right)
$$

All model estimations were performed using the software PythonBiogeme (Bielaire, 2003). An iterative procedure was used to obtain the final model. As we are dealing with two separated experiments with common alternatives and variables, it is reasonable to consider that the valuation of attributes by the same individuals across the different experiments will be similar. Therefore, common parameters are considered, acknowledging possible scale differences, using a similar technique akin to the technique used to model with RP and SP data simultaneously (Train, 2009; Ortúzar and Willumsen, 2011). In a first step, two distinct models were estimated - a model based on the data from the discrete-choice experiment on user preferences regarding currently available modes of transport, and a second model based on the data for alternatives available in the future. Common variables were used in both models in order to enable a comparison between the results. One exception to this was variables available in only one of the two choice experiments, for example access/egress time for conventional car in the first one, and the attributes of the SAV in the second one. In the next step of the analysis, a joint model based on the data from both choice experiments was estimated. To account for differences between the effects of unobserved factors in the two experiments, as well as for the different number of options, separate alternative-specific constants are estimated for current and future choices. The utility functions for the experiment on future preferences are scaled by a constant parameter $\mu$, which accounts for differences in the variability of the error terms.

In early estimations, the effect of the trip purpose on travel-time perception was tested by estimating coefficients for the interaction between in-vehicle time and the trip purpose, but no significant differences between different trip types were found for most of the alternatives. Statistically significant differences were only found between time perception when driving on commuting trips compared to driving on leisure/shopping trips suggesting a more negative perception of the time spent driving to/from work. These results can be related to trip characteristics, such as length, routine character, high risk for heavy traffic and time pressure on working days which make driving a tedious task when commuting. As the focus of the study was exploring the changes in time valuation resulting from automation and potential differences between the different trip purposes are important indicators for factors affecting these changes, the interaction between trip purpose, driving manually compared to riding autonomously, and in-vehicle time was included in the final model estimation. The effect of age and gender was also tested in early model estimations. However, as none of these variables showed 
any significant effect on potential user preferences regarding autonomous driving, they have been excluded from the final models. In contrast to this, a possession of a driving license and/or public transport pass had both a significant effect on mode choices and thus, they were included in the final model. Furthermore, an interaction between cost and the income class a person belongs to was included in the model in order to examine potential differences in perception of cost depending on income.

To indicate respondents' preferences regarding riding autonomously, as opposed to driving manually in a privately owned AV, two dichotomous variables were computed on the basis of an additional question in the survey which asked for these preferences on a five-point Likert-scale. The respondents could choose on a scale between "riding only autonomously" to "driving only manually". The dichotomous variable for autonomous driving was computed using the responses on the scale related to the choice for riding "only autonomously" or "most of the time autonomously". Consequentially, the variable which indicates preference for driving manually refers to the choices of driving "partly autonomously/partly manually", "most of the time manually", and "only manually". Two coefficients - for the interaction between in-vehicle time valuation, and the preference towards driving autonomously compared to driving manually - were estimated. Using a similar procedure, two different coefficients for the perception of in-vehicle time in an SAV - one for the situation when a person uses the vehicle alone, and one for when he/she has to share the ride - were estimated. Whether a ride with an SAV is a shared one or the person is travelling alone was one of the attributes that describe this alternative itself in the choice experiment (see Table 1). The attributes of the alternatives, the trip types and the socioeconomic factors which were included in the final model are presented in Table 3.

Table 3. List of variables included in the final model

\begin{tabular}{|c|c|}
\hline Variable & Description \\
\hline$T I M E_{i}$ & in-vehicle time for mode $i$ (minutes) \\
\hline $\operatorname{COST}_{i}$ & travel cost of mode $i(\epsilon)$ \\
\hline$A E T_{i}$ & access/egress time for mode $i$ (minutes) \\
\hline$W T_{i}$ & waiting time for mode $i$ (minutes) \\
\hline RIDE-SHARING & $\begin{array}{l}\text { dummy variable for sharing the ride in the SAV with other persons [corresponds to } \\
\text { the level/value of the attribute "ride-sharing" in the choice experiment where } 0= \\
\text { travelling alone, } 1=\text { ride-sharing/ the ride is shared with other passengers; "ride- } \\
\text { sharing" was one of the attributes that describe the alternative SAV] }\end{array}$ \\
\hline MANUALLY & $\begin{array}{l}\text { dummy variable indicating preference for driving the privately owned AV manually } \\
\text { [computed using the answers on the question "Imagine that you have your own } \\
\text { automated vehicle that you can use for the reported trip. Would you use this vehicle } \\
\text { in an autonomous or in manual mode?"; value '1' of this dummy variable } \\
\text { corresponds to the following original scale values: "partly autonomously/partly } \\
\text { manually", "most of the time manually", "only manually"] }\end{array}$ \\
\hline AUTONOMOUSLY & $\begin{array}{l}\text { dummy variable indicating preference for driving the privately owned AV } \\
\text { autonomously [computed using the answers on the question used also to compute } \\
\text { the dummy variable 'Manually'; value '1'of this dummy variable corresponds to the } \\
\text { following original scale values: "only autonomously", "most of the time } \\
\text { autonomously"] }\end{array}$ \\
\hline COMMUTING & dummy variable for commuting trips \\
\hline LEISURE/SHOPPING & dummy variable for leisure or shopping trips \\
\hline$D L$ & dummy variable indicating possession of driving licence \\
\hline PT PASS & dummy variable indicating possession of public transport pass \\
\hline$I N C O M E_{j}$ & $\begin{array}{l}\text { dummy variable indicating which income class a respondent belongs to (low: up to } \\
€ 1,500 / \text { month, middle: } € 1,500-€ 3,000 / \text { month, high: more than } € 3,000 / \text { month) }\end{array}$ \\
\hline
\end{tabular}

The joint mixed logit model was estimated using an iterative procedure to explore relevant random effects. This allowed considering the pseudo-panel nature of the data, i.e. to account for the correlation among the preferences associated with the same respondent (Walker et al., 2007). The coefficients for in-vehicle time as well as for access/egress and waiting time were included as random parameters in the model in order to examine potential heterogeneity in preferences across respondents. Only time 
elements for which a significant heterogeneity in the preferences was found were considered as random parameters in the final model. This includes random parameters for the following time elements: en-route time for walking and cycling; in-vehicle time for public transport, for an SAV as ride-sharing, and for autonomous driving on commuting trips; access/egress time for conventional car and for public transport (however, only in the future scenario), and waiting time for AV/SAV.

The distribution of the random parameters was simulated using 8,000 MLHS (Modified Latin Hypercube Sampling) draws (Hess et al., 2006); the large number of draws was decided on to reflect the high number of dimensions over which the likelihood function must be integrated. Initially, a normal distribution was assumed for all random parameters including the random components for the pseudo-panel (i.e. agent) effect. From behaviour perspective, however, the normal distribution might not be the most appropriate one when estimating time parameters in the context of mode choices. Alternatives to the normal distribution coping with some of its shortcomings, including the fact that its unbounded and symmetrical nature might cause a significant proportion of the distribution to exhibit wrong signs, are the lognormal and the triangular distribution (Hess et al., 2005). Therefore, these two distributions were tested for the random time coefficients in the further model estimations, while the random components related to the pseudo-panel effect were assumed to follow a normal distribution in all estimated models. Insignificant variance parameters were found using the lognormal distribution instead of the normal one which suggests less adequate fit to the study data. Assuming triangular distribution, on the other hand, provided better results than a normal or log-normal distribution (both in terms of model adjustment and plausibility of the estimated parameters, i.e. percentage of the population exhibiting the expected sign for the time parameters). The comparison of the models was performed in two steps. First, a comparison on the basis of the Akaike information criterion (AIC) favours the model assuming triangularly distributed random parameters. Second, we used the cumulative distribution functions for the selected distribution types and the model data to calculate the amount of values that exhibit a non-intuitive (positive) sign for the time parameters. The results show a smaller amount of time parameter values over zero in the model assuming triangularly distributed random parameters compared to the other models. Thus, in the final model, a triangular distribution for the random time coefficients is used.

Symmetrical triangular distributions were simulated in Biogeme as the sum of two independently and uniformly distributed random variables $\left(\mathrm{U}_{1}\right.$ and $\left.\mathrm{U}_{2}\right)$ ranging between -1 and 1 . Consequently, the triangular distribution is given by $\beta+\sigma * 0.5 *\left(U_{1}+U_{2}\right)$, where $\beta$ represents the mean and $\sigma$ the semirange of the distribution. After estimating the parameters $\beta$ and $\sigma$, we have calculated the standard deviation for each random parameter for which a symmetrical triangular distribution was assumed using the following formulation: $\eta=\sqrt{6}(\sigma * 2) / 12$.

\section{Results and discussion}

\subsection{Estimated model coefficients}

The results of the final separate models are summarised in Table 4 . The table gives an overview of the estimated model coefficients ( $($ ), the estimated (or calculated) standard deviations $(\eta)$ of the random coefficients, and the model fit of the model. Overall, the estimated model parameters show plausible signs and values. 
Table 4. Results of the two distinct mixed logit model estimation

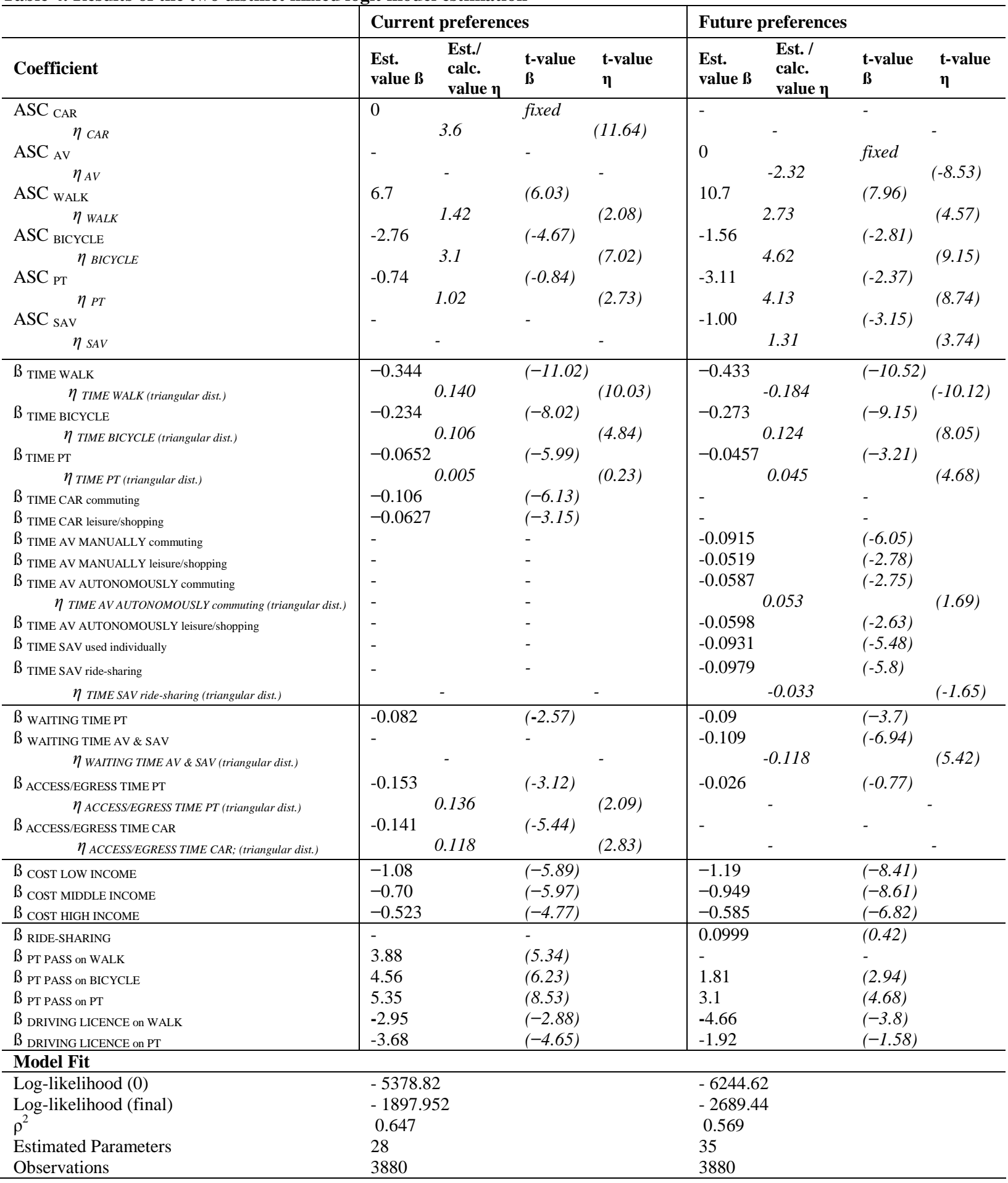

To justify the estimation of the joint model, the relationship between the common parameters (time elements parameters for common modes of transport and cost parameters) in the two distinct models was examined. The comparison shows that they exhibit similar tendencies and are highly correlated with each other (see Figure 1). In general terms, the magnitude of the estimated parameters is slightly larger in the future preferences models, which is indicative for a smaller variance, but the differences are minimal. Therefore, it seems plausible to estimate a joint model considering common parameters across the experiments. 


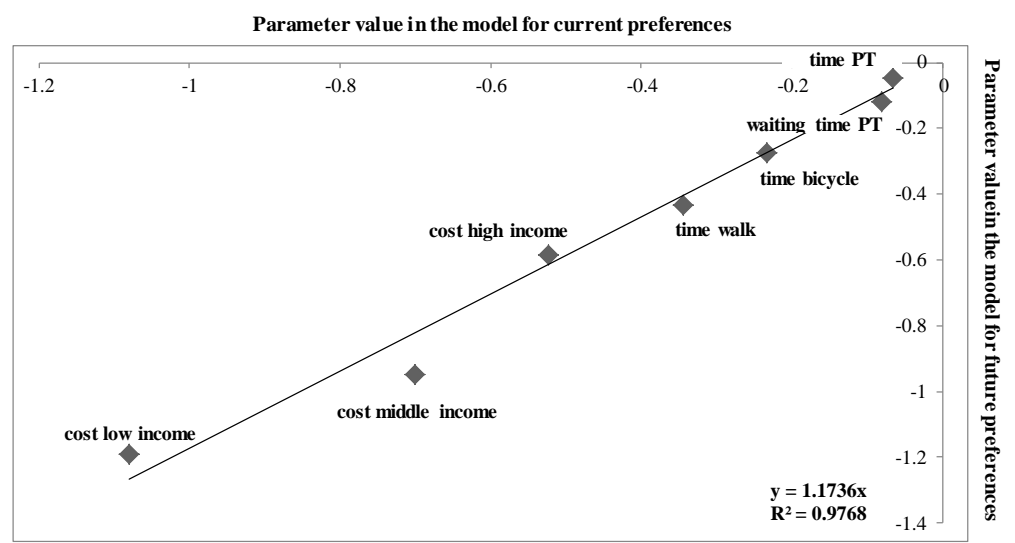

Figure 1: Relationship between the common parameters in the model on current preferences and the model on future preferences

Table 5 summarizes the results from the estimated joint model. The table presents again the estimated model coefficients, including the estimated deviations of the random coefficients as well as the scaling parameter $\mu$. Additionally, it is indicated when the parameters are related only to current or only to future conditions (i.e., are estimated only using the data from the first or only from the second choice experiment). The results show that the models estimated separately for the current and future choice situation do not statistically outperform the joint model considering common parameters in both choice situations $\left(\chi^{2}(9)=4.782, \mathrm{p}>0.05\right)$. However, considering the joint model allows for a direct comparison of the changes in marginal utilities associated with the introduction of AVs.

Overall, all estimated coefficients for the time and cost attributes have a significant effect on the mode choice. The alternative-specific time coefficients were compared with each other using a $t$-Test for generic parameters in order to analyse whether there are statistically significant differences between the coefficients. The following formulation was used for the estimations: $\left.\left(\beta_{1}-\beta_{2}\right) / \sqrt{\left(s_{1}^{2}+s_{2}^{2}-2 * s_{12}^{2}\right.}\right)$, where $\beta_{1}$ and $\beta_{2}$ are the estimated parameters which are compared with each other, $s_{1}^{2}$ and $s_{2}^{2}$ are their variances, and $s_{12}^{2}$ is their covariance. The comparisons and the calculated t-values are reported in the following part.

The results of the estimations and the comparison of the estimated coefficients for current and future preferences (which can be directly compared given the estimation approach) show that, for commuting trips, riding autonomously $\left(\beta_{\text {time }}\right.$ AV autonomously commuting $\left.=-0.0621\right)$ is perceived less negatively than driving a conventional car nowadays $\left(\beta_{\text {time car commuting }}=-0.105 ; \mathrm{t}=1.65, \mathrm{p}<0.05\right.$ considering a onetailed t-test as the direction of the effect is known a priori). Along these lines, the results also suggest that people perceive time spent in a conventional car $\left(\beta_{\text {time car commuting }}=-0.105\right)$ and in an $\mathrm{AV}$ which is used as a conventional one (i.e., is driven manually; $\left.\beta_{\text {time } A V \text { manually commuting }}=-0.0966\right)$ similarly $(\mathrm{t}=-$ $0.37, \mathrm{p}>0.05)$. Differences between riding AVs autonomously and manually are nearly significant $(\mathrm{t}$ $=1.59, \square=6 \%$ one-tailed test $)$ and point in the same direction. Furthermore, the results show that when driving manually (current and future preferences), leisure trips are perceived less negatively than communing trips $\left(\beta_{\text {time car leisure/shopping }}=-0.0649\right.$ and $\beta_{\text {time car commuting }}=-0.105, \mathrm{t}=1.84, \mathrm{p}<0.05 ; \beta_{\text {time AV }}$ manually leisure/shopping $=-0.0539$ and $\beta_{\text {time }} \mathrm{AV}$ manually commuting $\left.=-0.0966, \mathrm{t}=2.23, \mathrm{p}<0.05\right)$. This difference, however, vanishes when driving autonomously. In general, the perception of time spent on leisure trips is perceived similarly, disregarding whether the vehicles are driven manually or autonomously. Moreover, there is a significant heterogeneity across the respondents in the perception of in-vehicle time riding autonomously on commuting and thus, the reported difference refers to the average value of the sample.

A comparison of autonomous driving with using other modes of transport shows that riding autonomously in a privately owned vehicle $\left(\beta_{\text {time } A V \text { autonomously commuting }}=-0.0621\right)$ is perceived similarly to spending in-vehicle time on public transport $\left(\beta_{\text {time PT }}=-0.0577 ; \mathrm{t}=-0.21, \mathrm{p}>0.05\right)$. At the same time, riding in an SAV $\left(\beta_{\text {time SAV ride-sharing }}=-0.11\right)$ is found to be less attractive than using either privately owned AV riding autonomously $\left(\beta_{\text {time } A V \text { autonomously commuting }}=-0.0621 ; \mathrm{t}=2.12, \mathrm{p}<0.05\right)$ or 
public transport $\left(\beta_{\text {time PT }}=-0.0577 ; \mathrm{t}=-2.92, \mathrm{p}<0.05\right)$. Furthermore, when considering the in-vehicle time in an SAV, no significant differences were found between using the shared vehicle alone $\left(\beta_{\text {time }}\right.$ SAV used individually $=-0.103)$ and sharing the ride with strangers $\left(\beta_{\text {time }} S A V\right.$ ride-sharing $\left.=-0.11 ; \mathrm{t}=-0.45, \mathrm{p}>0.05\right)$. A similar tendency is evident in that the coefficient for a shared ride $\left(\beta_{\text {ride-sharing }}=0.118\right)$ is likewise not significant. Simultaneously, there is a significant heterogeneity in the sample regarding perception of in-vehicle time when sharing the ride, but no differences across the respondents for the perception of time spent riding in an SAV alone.

Table 5. Results of the joint mixed logit model estimation

\begin{tabular}{|c|c|c|c|c|}
\hline Coefficient & Est. value B & Est./ calc. value $\eta$ & t-value $B$ & t-value $\eta$ \\
\hline $\mathrm{ASC}_{\mathrm{CAR} ; \text { current }}$ & 0 & & fixed & \\
\hline$\eta_{\text {CAR; } \text { current }}$ & & 3.36 & & $(10.65)$ \\
\hline $\mathrm{ASC}_{\mathrm{AV} \text {; future }}$ & 0 & & fixed & \\
\hline$\eta_{A V ;}$ future & & 2.39 & & $(8.83)$ \\
\hline ASC WALK; current & 6.58 & & $(5.73)$ & \\
\hline$\eta$ WALK; current & & -1.23 & & $(-2.16)$ \\
\hline ASC WALK; future & 10.2 & & $(8.08)$ & \\
\hline$\eta_{\text {WALK; future }}$ & & 2.77 & & $(5.44)$ \\
\hline ASC BICYCLE; current & -2.83 & & $(-5.56)$ & \\
\hline$\eta_{B I C Y C L E ; \text { current }}$ & & 3.01 & & $(7.61)$ \\
\hline ASC BICYCLE; future & -1.47 & & $(-2.75)$ & \\
\hline$\eta_{B I C Y C L E ; \text { future }}$ & & -4.58 & & $(-10.69)$ \\
\hline $\mathrm{ASC}_{\mathrm{PT} ; \text { current }}$ & -1.03 & & $(-1.13)$ & \\
\hline$\eta_{P T} ;$ current & & -1.44 & & $(-2.36)$ \\
\hline $\mathrm{ASC}_{\mathrm{PT} ; \text { future }}$ & -3.23 & & $(-2.11)$ & \\
\hline$\eta_{P T} ;$ future & & -4.41 & & $(-8.28)$ \\
\hline $\mathrm{ASC}_{\mathrm{SAV}}$; future & -0.927 & & $(-2.83)$ & \\
\hline$\eta$ SAV; future & & -1.15 & & $(-2.53)$ \\
\hline$\beta_{\text {TIME WALK }}$ & -0.366 & & $(-12.54)$ & \\
\hline$\eta$ TIME WALK; (triangular dist.) & & 0.152 & & $(12.2)$ \\
\hline$ß_{\text {TIME BICYCLE }}$ & -0.233 & & $(-11.69)$ & \\
\hline$\eta$ TIME BICYCLE; (triangular dist.) & & 0.100 & & $(10.41)$ \\
\hline$\beta_{\text {TIME PT }}$ & -0.0577 & & $(-5.83)$ & \\
\hline$\eta_{\text {TIME PT; (triangular dist.) }}$ & & 0.039 & & $(3.85)$ \\
\hline$B_{\text {TIME CAR commuting; current }}$ & -0.105 & & $(-5.96)$ & \\
\hline$ß_{\text {TIME CAR leisure/shopping, current }}$ & -0.0649 & & $(-3.32)$ & \\
\hline$ß$ TIME AV MANUALLY commuting; future & -0.0966 & & $(-6.33)$ & \\
\hline$ß$ TIME AV MANUALLY leisure/shopping; future & -0.0539 & & $(-2.94)$ & \\
\hline B TIME AV AUTONOMOUSLY commuting; future & -0.0621 & & $(-2.98)$ & \\
\hline$\eta$ TIME AVAUTONOMOUSLY commuting; future; (triangular dist.) & & 0.063 & & $(2.55)$ \\
\hline ß TIME AV AUTONOMOUSLY leisure/shopping; future & -0.0643 & & $(-2.60)$ & \\
\hline$ß$ TIME SAV used individually; future & -0.103 & & $(-5.98)$ & \\
\hline$\beta_{\text {TIME SAV ride-sharing; future }}$ & -0.11 & & $(-6.45)$ & \\
\hline$\eta$ TIME SAV ride-sharing; future; (triangular dist.) & & 0.039 & & $(2.37)$ \\
\hline$\beta_{\text {WAITING TIME PT }}$ & -0.088 & & $(-3.8)$ & \\
\hline$B_{\text {WAITING TIME AV \& SAV }}$ & -0.112 & & $(-7.06)$ & \\
\hline$\eta$ WAITING TIME AV \& SAV; future; (triangular dist.) & & 0.298 & & $(5.59)$ \\
\hline$ß_{\text {ACCESS/EGRESS TIME PT; current }}$ & -0.151 & & $(-3.12)$ & \\
\hline$\eta_{\text {ACCESS/EGRESS TIME PT; current; } \text { (triangular dist.) }}$ & & 0.120 & & $(1.66)$ \\
\hline$\beta_{\text {ACCESS/EGRESS TIME PT; future }}$ & -0.031 & & $(-0.87)$ & \\
\hline$\beta_{\text {ACCESS/EGRESS TIME CAR; current }}$ & -0.142 & & $(-5.4)$ & \\
\hline$\eta_{\text {ACCESS/EGRESS TIME CAR; current; (triangular dist.) }}$ & & 0.140 & & $(3.03)$ \\
\hline$\beta_{\text {COST LOW INCOME }}$ & -0.991 & & $(-8.56)$ & \\
\hline$ß$ COST MIDDLE INCOME & -0.806 & & $(-9.25)$ & \\
\hline$\beta_{\text {COST HIGH INCOME }}$ & -0.561 & & $(-7.89)$ & \\
\hline$\mu$ (sCALING PARAMETER; applied on the data set for future preferences) & 1.15 & & $(0.102)$ & \\
\hline$\beta_{\text {RIDE-SHARING; future }}$ & 0.118 & & $(0.49)$ & \\
\hline B PT PASS on WALK; current & 4.26 & & $(5.98)$ & \\
\hline$ß_{\text {PT PASS on BICYCLE; current }}$ & 4.72 & & $(7.27)$ & \\
\hline$ß$ PT PASS on BICYCLE; future & 1.99 & & $(3.07)$ & \\
\hline$ß_{\text {PT PASS on PT; current }}$ & 5.44 & & $(8.58)$ & \\
\hline$ß_{\text {PT PASS on PT; future }}$ & 3.02 & & $(4.74)$ & \\
\hline B DRIVING LICENCE on WALK; current & -2.77 & & $(-2.5)$ & \\
\hline B DRIVING LICENCE on WALK; future & -4.28 & & $(-3.55)$ & \\
\hline B DRIVING LICENCE on PT; current & -3.62 & & $(-4.48)$ & \\
\hline$\beta_{\text {DRIVING LICENCE on PT; future }}$ & -1.92 & & $(-1.35)$ & \\
\hline
\end{tabular}




\begin{tabular}{ll}
\hline Log-likelihood (0) & -11623.44 \\
Log-likelihood (final) & -4589.783 \\
$\rho^{2}$ & 0.605 \\
Estimated Parameters & 54 \\
Observations & 7760 \\
\hline
\end{tabular}

Coefficients for access/egress and waiting times were estimated as mode-specific parameters instead of generic ones. This was in order to allow a comparison between a privately owned conventional car and an AV which differ in these aspects. The conventional car is presented as having an access/egress time, while the AV has a waiting time instead (as it picks up its passenger and drops them off at their destination). Overall, access/egress time and waiting time for public transport and for conventional car are perceived more negatively than the in-vehicle time. An exception is the estimated coefficient for access/egress time for public transport under future conditions (i.e., when AVs are available) which is not statistically significantly different from zero. As there was no difference between the perceptions of waiting time for a privately owned vehicle and for SAV in the early model estimations, the waiting time parameter was considered for both alternatives. The results indicate that waiting time for both autonomous driving concepts is perceived as slightly more negative than in-vehicle time, and that there is a significant heterogeneity in the perception of waiting time for AV/SAV across the respondents.

The cost coefficients were estimated depending on the income class to which the respondents belonged. The results show, unsurprisingly, that individuals with a high income perceive cost less negatively than individuals with middle or low incomes, and that those with a middle income perceive cost less negatively than those with a low income. The perception of cost as influenced by trip purpose was tested in early model estimations, but no significant differences were found between the trip purposes.

The characteristics of individual mobility, such as possession of a driving licence or a public transport pass, are also strongly related to mode choice preferences. Having a driving licence decreases the probability of choosing any modes of transport other than the car or an AV, with the exception of choosing a bicycle. Further, the probability of choosing AV or SAV is similarly affected by driving licence possession. Possession of a public transport pass, on the other hand, increases the probability of choosing any mode of transport other than the car or an AV - except that the probability of travelling by SAV is unaffected, remaining the same as the probability of travelling by AV. Overall, the effect of individual mobility characteristics seems not to change significantly when AVs become available.

\subsection{VTTS and policy implications}

Finally, we calculated the VTTS (in euros per hour) for each mode of transport, for each income class, using the following function:

$$
V T T S=\frac{\partial U_{i} / \partial T T_{i}}{\partial U_{i} / \partial T C_{j}}=\frac{\beta_{\text {Time }, i}}{\beta_{\text {Cost }, j}}
$$

The VTTS presented in Table 6 were calculated based on the results of the final estimated joint mixed logit model. We calculated the VTTS for each mode of transport in Euros per hour separately for each income class. The VTTS calculations for the random time coefficients are based on the mean values of the random distribution, i.e., the estimated B-time parameters. As the cost parameters used for calculating the VTTS within a single income class are fixed, the results from the comparison of statistical differences between the B-time parameters reported in section 4.1. apply also for the VTTS reported in Table 6. 
Table 6. Estimated value of travel-time savings for different modes of transport and income classes [in $€ / \mathrm{h}$ ]

\begin{tabular}{l|l|l|l}
\hline Mode of transport & \multicolumn{3}{|c}{ Income class } \\
\hline Walk & Low income & Middle income & High income \\
Bicycle & 22.2 & 27.3 & 39.1 \\
Public transport & 14.1 & 17.3 & 24.9 \\
Conventional car; commuting trips & 3.5 & 4.3 & 6.2 \\
Conventional car; leisure/shopping trips & 6.4 & 7.8 & 11.2 \\
Autonomous vehicle (manually driven); commuting trips & 3.9 & 4.8 & 6.9 \\
Autonomous vehicle (manually driven); leisure/shopping trips & 3.8 & 7.2 & 10.3 \\
Autonomous vehicle (riding autonomously); commuting trips & 3.8 & 4.0 & 5.8 \\
Autonomous vehicle (riding autonomously); leisure/shopping & 3.9 & 4.6 & 6.6 \\
trips & & 4.8 & 6.9 \\
Shared autonomous vehicle (used individually) & 6.2 & 7.7 & \\
Shared autonomous vehicle (ride-sharing) & 6.7 & 8.2 & 11.0 \\
\hline
\end{tabular}

As indicated above, there are differences in the perception of costs, depending on income class to which a person belongs. Thus, we have estimated the VTTS for each income class by using the costcoefficients corresponding to the particular income category. Consequentially, the estimated values for people with higher household income are higher than of those belonging to middle- or low-income classes, but the proportional differences between the mode-specific values remain the same across the income classes. The values for public transport and for conventional car are in the same range as existing values derived from a representative study on the values of travel time savings for Germany (Axhausen et al., 2015). This indicates that the results of the model estimations performed in the study presented in this paper are plausible.

For commuting trips only, using riding autonomously leads to an average reduction in the VTTS by $41 \%$ compared to driving a conventional car nowadays and it is perceived similar as time spent in public transport. However, owing to the additional access/egress and waiting time involved in travelling by public transport, it can be assumed that using an AV for commuting trips is more attractive than using public transport. These results are in line with the results of a previous study on using AVs for commuting trips conducted in Germany (Steck et al., 2018). No significant effect was found regarding autonomous driving for leisure or shopping trips. This may be related to the fact that the VTTS for leisure and shopping trips are, in general, lower than the values for commuting trips. Also, as discussed above, due to the specific characteristics of commuting trips, commuters might be more likely to benefit from using travel time for other activities, and, in addition, automation can lower the stress caused by being stuck in traffic (see also Trommer et al., 2016). Moreover, the type of activities which individuals would like to perform in an AV can affect the travel time perception. For instance, as mentioned above, Correia et al. (2019) found differences in the VTTS for an AV with working compared to an AV with leisure interior. These results were in line with the authors' theoretical assumption derived from the microeconomics theory that a work AV would have lower VTTS than a leisure one (Correia et al., 2019). Although the authors considered the different types of activities only for commuting trips, the trip purpose might also affect the desirable activities. In our study, desirable activities were not explicitly captured, but differences in time perception depending on trip purpose can be first indications for reasons behind potential preference changes. Hence, given the insights from recent studies and our results, the relationship between travel activities or other benefits from using an $\mathrm{AV}$ and trip characteristics (such as trip purpose) have to be further explored in a following works.

The SAV seems to be perceived as a less attractive option than using a privately owned AV, but considering the additional access/egress and waiting time for public transport, it can be, from a user perspective, a viable alternative to it. Further, no differences were found in the in-vehicle time across the various trip purposes, neither was any difference seen when comparing use of the SAV alone with sharing the ride with strangers. This last result suggests that the respondents perceived both options 
similarly - but this could be because the concept is, at this point in time, too abstract for most respondents to grasp adequately. Gaining insights into preferences regarding SAVs is important for future planning, since the SAV might be a viable mobility option supporting more efficient car use and contributing to a reduction in vehicle ownership. Since the results of this study are only partly in line with the results of previous studies, especially regarding ride-sharing, further research in this field is needed. Also, the willingness to use SAVs as a complementary instead of competitive option to public transport in areas where the public transport services are deficient today (e.g. periphery or rural areas) has to be explored in further works owing to the fact that public transport is in general more efficient in terms of number of passengers carried.

Turning to policy and transport planning implications, the study findings provide empirical arguments to support the case that, unless there is some form of policy intervention, the reduction of the VTTS of a privately owned car, especially for commuting trips, can lessen or eliminate some of the potential benefits of autonomous driving. As also discussed in previous studies, the reduction in the VTTS (and thus of the generalised cost of travel) can lead to an increase of the attractiveness of travelling in general, and a shift from non-motorised to motorised modes of transport, as well as increasing the tendency to travel longer distances, by bringing about a change in choice of destination (BahamondeBirke et al., 2018; Wadud et al., 2016; Gruel and Stanford, 2016). This carries the potential of causing a substantial increase in travelled vehicle-kilometres, along with an overproportional increase in the negative externalities of transportation (as the relationship between the negative effects of polluting emissions and congestion is not linear) that may end up diminishing the social welfare.

Along these lines, the fact that VTTS by means of autonomous driving would be reduced to the level of public transport, may also result in demand shift from public to private transportation putting the transit system under financial pressure. Therefore, when formulating policy measures, including pricing policy, designed to facilitate sustainable transport, the potential conflict between, on the one hand, improving the quality of individual mobility, and, on the other hand, challenges related to the transport system that arise from a reduced VTTS, has to be considered. Since improvements in traffic efficiency and road capacity arising from automation can be achieved only when the share of AVs on the street increases (Hartmann et al., 2017, Calvert et al., 2017) and especially if connectivity between the AVs (and infrastructure) is given (Milakis et al., 2017), policy measures are needed to ensure an efficient use of the technology from the point of its implementation into the transport system onwards. One possible strategy could be incentivising multimodality by facilitating the use of AVs, especially SAVs, as a solution to the first-/last-mile problem, and thereby improving the quality of public transport as a viable and reliable door-to-door mobility option (Scheltes and Correia, 2017). Such measures, however, would have to tackle the large negative incentives against transferring (represented through the waiting time coefficients in our model) that may prevent individuals to use $\mathrm{AVs}$ in that way and encourage riding AVs from origin to destination instead.

Other viable policy measures, especially in urban areas, might include ones intended to facilitate the use of SAV, especially as a ride-sharing service. However, the results of our study suggest that this mobility alternative might be less preferable to users than a privately owned AV, which challenges the vision that AVs are mostly going to be used as shared vehicles. Hence, the potential for such measures - for example supporting the use of SAV by reducing prices, or permitting only SAVs in urban centres - needs to be explored in future studies concentrating on this topic, as substantial incentives may be required, while prohibition may face strong public opposition. Here again, the potential of using SAVs as a part of an integrated transport system, and as an alternative to the privately owned vehicles instead to public transport, has to be in focus of these analyses.

All in one, the results of the study support the hypothesis that AVs will facilitate individual motorized mobility. Consequentially, in the absence of measures to impose additional restrictions on car usage or force users to internalise the externalities of their behaviour by means of pricing, such as tolling systems, there is a high risk of undesired shifts from non-motorized transportations modes and increases in travel demand (Bahamonde-Birke et al., 2018 Gruel and Stanford, 2016). 


\section{Conclusions}

The aim of the study was to estimate potential changes in the value of travel-time savings (VTTS) when autonomous driving becomes available. For this purpose, user preferences regarding currently available modes of transport and user preferences regarding modes of transport available in the future were compared using two discrete-choice experiments. The VTTSs for two concepts of autonomous driving - privately owned autonomous vehicle (AV) and a shared autonomous vehicle (SAV) - were calculated on the basis of the results of a joint mixed logit model.

First, the results suggest a VTTS reduction of $41 \%$ for commuting trips for autonomous driving as compared to driving a conventional car nowadays. However, no changes in the VTTS were found for leisure or shopping trips, suggesting that a general VTTS reduction resulting from availability of autonomous driving cannot be confirmed by the study results. Second, in-vehicle time in an SAV is found to be perceived more negatively than using either a privately owned AV (riding autonomously) or public transport. However, here too, a consideration of the access/egress and waiting time besides the in-vehicle time associated with public transport suggests the potential for the SAV as a service that is an alternative - or complementary - to public transport. Third, policy implications that can be drawn from the results of the study suggest that there is a potential conflict between user benefits of autonomous driving and societal goals. This is related to the fact that a reduction of the VTTS for autonomous driving on commuting trips will potentially lead to an increase in vehicle-kilometres travelled. Similarly, as the reduction of VTTS mostly affects private transportation, it can also cause a shift in the demand from public transportation and non-motorized alternatives to privately owned vehicles. Both phenomena may pose a challenge to transport planners, as increases in the demand for private transportation at the expense of the demand for more efficient alternatives can cause an increase in the negative externalities of transportation and, hence, welfare losses.

Because the technology is not yet available in the market, any assessment of the impact of automation using stated preference methods has its limitations and it is highly dependent on the chosen study design, especially on the way new alternatives are presented. A privately owned AV can be presented to respondents in different ways, including presenting a fully automated vehicle in the same choice set with a conventional one or adding the function of automation as an attribute of the alternative "car". We have chosen to present a car able to drive autonomously or manually upon request in order to avoid an implicit purchasing decision for a type of car which might potentially influence the choices of respondents. It is therefore important to interpret the results of the study from the background of the chosen design. Acknowledging the challenges related to stated preference methods in general, we have focused the analysis on higher-level constructs such as that of the VTTS. Furthermore, using a reference trip and addressing first the user preferences regarding current modes of transport (including a privately owned conventional car) allows considering individual knowledge and perceptions as a baseline and this improves the accuracy of the estimation of changes in VTTS. The approach used in this study provides a better understanding of user preference changes, as considering only future preferences would not capture the baseline, that is to say mode choice preferences under current conditions. Moreover, capturing both current mode choice preferences and future preferences considering new mobility options provides more accurate input for travel demand models, which are an important tool for analysing the possible impact of automation on travel behaviour.

Last but not least, further empirical work on the effects of the way in which autonomous driving, and especially of SAVs, are introduced to the respondents is required. Using visual materials such as videos, as done in this study, might be better than providing only text description, but their limitations have to be considered when interpreting the results. Experience-centered methods, such as field tests or using virtual reality can be explored in future works on potential user preferences even though the higher cost of those methods might be a limitation.

In summary, this study has provided valuable empirical insights into potential changes in the VTTS for autonomous driving. Further empirical research could explore the factors affecting the reduction of the VTTS for autonomous driving in more detail, including characteristics related to context, such as geographical factors, as well as current congestion levels or other restrictions on comfort levels. Furthermore, exploring attitudinal and perceptual variables could provide valuable insights into the 
mode choice decision-making process, once the technology becomes available in the market. These can additionally contribute to the development of efficient measures for implementing and promoting the technology in a way which considers users' needs and their mobility requirements. Along these lines, exploring the willingness to perform different activities while riding autonomously (e.g. working, reading) or to relax during the trip can contribute to evaluating the potential impact of autonomous driving on travel quality, economical welfare and well-being. Finally, the use of SAVs and their impact on vehicle ownership and mobility behaviour in general is an important avenue of research on which future studies should focus. Because this study focused on mode choice, vehicle purchase decisions were not considered. As discussed above, policy and transport planning authorities face new challenges resulting from the implementation of vehicle automation. Empirical evidence, as provided in this paper, is thus of great importance when considering and discussing both the opportunities, and also the risks, associated with implementing this technology.

\section{Acknowledgment}

This study was conducted within the former funded project "Next generation Car (NGC) Fahrzeugintelligenz und mechatronisches Fahrwerk (FiF)" at the German Aerospace Center (Deutsches Zentrum für Luft- und Raumfahrt; DLR). The authors would also like to thank the anonymous reviewers of the manuscript for the constructive and helpful comments which significantly improved the paper.

\section{References}

1. Abrantes, P. A. L. and Wardman, M. R. (2011) Meta-Analysis of UK Values of Travel Time: An Update. Transportation Research Part A, 45, 1-17.

2. ADAC (2017) ADAC Autokosten Frühjahr/Sommer 2017. München, Germany.

3. Anderson, J. M., Kalra, N., Stabnley, K. D., Sorensen, P., Samaras, C. and Oluwatola, O. (2014) Autonomous Vehicle Technology - A Guide for Policymakers. RAND Corporation.

4. Arup, ITS Leeds and Accent (2015) Provision of market research for value of time savings and reliability. Phase 2 report to the Department for Transport.

5. https://www.gov.uk/government/uploads/system/uploads/attachment_data/file/470231/vttsphase-2-report-issue-august-2015.pdf. Accessed 20 August 2018

6. Axhausen, K., Ehreke, I., Glemser, A., Hess, S., Jödden, C., Nagel, K., Sauer, A. and Weis, C. (2015) Ermittlung von Bewertungsansätzen für Reisezeiten und Zuverlässigkeit auf der Basis eines Modells für modale Verlagerungen im nicht-gewerblichen und gewerblichen Personenverkehr für die Bundesverkehrswegeplanung. FE-Projekt-Nr. 96.996/2011, BMVBS, Berlin.

7. Bahamonde-Birke, F. J., Kickhöfer, B. and Kuhnimhof, T. (2018) A systemic view on autonomous vehicles: Policy aspects for a sustainable transportation planning. DisP - The Planning Review, 54(3), 12-25.

8. Becker, F. and Axhausen, K. W. (2016) Literature review on behavioral experiments for autonomous vehicles. Arbeitsberichte Verkehrs- und Raumplanung.

9. Bielaire, M. (2003) A free package for the estimation of discrete choice models. 3rd Swiss Transportation Research Conference, 19-21 March 2003, Ascona, Switzerland.

10. Bliemer, M. C. J., and Rose, J. M. (2005) Efficiency and Sample Size Requirements for Stated Choice Studies. Working Paper ITLS-WP-05-08, ISSN 1832-570X, The University of Sydney.

11. Boyd, J. and Mellman, R. (1980) The Effect of Fuel Economy Standards on the U.S. Automotive Market: An Hedonic Demand Analysis. Transportation Research Part A, 14, 367378.

12. Burns, L. D., Jordon, W. C. and Scarborough, B. A. (2013) Transforming personal mobility. The Earth Institute, Columbia University.

13. Calvert, S.C., Schakel, W.J. and van Lint, J.W.C. (2017) Will Automated Vehicles Negatively Impact Traffic Flow? Hindawi Journal of Advanced Transportation, Vol. 2017, Article ID 
3082781.

14. Cardell, N. and Dunbar, F. (1980) Measuring the Societal Impacts of Automobile Downsizing. Transport Research Part A, 14, 423-434.

15. Childress, S., Nichols, B., Charlton, B. and Coe, S. (2014) Using an activity-based model to explore possible impacts of automated vehicles. 94 ${ }^{\text {th }}$ Annual Meeting of the Transport Research Board, 11-15 January 2015, Washington, D.C..

16. ChoiceMetrics (2012) Ngene 1.1.1 User Manual and Reference Guide. Australia.

17. Correia, G. H. d. A and Viegas, J. M. (2011) Carpooling and carpools clubs: Clarifying concepts and assessing value enhancement possibilities through a Stated Preference web survey in LIsabon, Portugal. Transportation Research Part A, 45, 81-90.

18. Correia, G. H. d. A and van Arem, B. (2016) Solving the User Optimum Privately Owned Automated Vehicles Assignment Problem (UO-POAVAP): A model to explore of self-driving vehicles on urban mobility. Transportation Research Part B, 87, 64-88.

19. Correia G., Looff E., Cranenburgh S., Snelder M., Arem B. (2019) On the impact of vehicle automation on the Value of Travel Time while performing work and leisure activities in a car: theoretical insights and results from a stated preference survey. Transportation Research Part A: Policy and Practice. In press.

20. De Looff, E., Correia, G. H. d. A., Van Cranenburgh, S., Snelder, M. and Van Arem, B. (2018) Potential changes in value of travel time as a result of vehicle automation: a casestudy in the Netherlands. 97 ${ }^{\text {th }}$ Annual Meeting of the Transportation Research Board, 7-11 January 2018, Washington, D.C..

21. Dokic, J., Müller, B. and Meyer, G. (2015) "European roadmap smart systems for automated driving." European Technology Platform on Smart Systems Integration.

22. DLR and infas (2010) Mobilität in Deutschland (MiD) 2008. Ergebnisbericht. Bonn and Berlin, Germany.

23. ERTRAC (2015) Automated driving roadmap, ERTRAC. http://www.ertrac.org/uploads/documentsearch/id38/ERTRAC_Automated-Driving-2015.pdf. Accessed 04 Sept 2017

24. Fagnant, D. J. and Kockelman, K. (2015) Preparing a nation for autonomous vehicles: Opportunities, barriers and policy recommendations. Transportation Research Part A, 77, 167-181.

25. Gruel, W. and Stanford, J. M. (2016) Assesing the Long-Term Effects of Autonomous Vehicles: a speculative approach. Transport Research Procedia, 13, 18-29.

26. Gucwa, M. (2014) Mobility and Energy Impacts of Automated Cars. Automated Vehicles Symposium, 19-21 July 2014, San Francisco, CA.

27. Harper, C. D., Hendrickson, C. T., Mangones, S. and Samaras, C. (2016) Estimating potential increases in travel with autonomous vehicles for the non-driving, elderly and people with travel-restrictive medical conditions. Transportation Research Part C, 72, 1-9.

28. Hartmann, M., Motamedidehkordi, N., Krause, S., Hoffmann, S., Vortisch, P. and Busch, F. (2017) Impact of Automated Vehicles on Capacity of the German Freeway Network. ITS World Congress 2017, 29 October - 2 Novemver 2017, Montreal, Canada.

29. Hensher, D. A. (2011) Valuation of travel time savings. A Handbook of Transport Economics eds. A.D. Palma, R. Lindsey, E. Quinet and R. Vickerman, pp 135-159. Edward Elgar.

30. Hensher, D. A. and Greene, W. H. (2002.) The Mixed Logit Model: The State of Practice. Transportation, 30, 133-176.

31. Hess, S., Bierlaire, M. and Polak, J.W. (2005) Estimation of the value of travel-time savings using Mixed Logit models. Transportation Research Part A, 39 (2-3), 221-236.

32. Hess, S., Train, K. E. and Polak, J. W. (2006) On the use of Modified Latin Hypercube Sampling (MLHS) method in the estimation of a Mixed Logit Model for vehicle choice. Transportation Research Part B: Methodological, 40, 147-163.

33. Jara-Diaz, S. R. (2000) Allocation and valuation of travel-time savings. Handbook of Transport Modelling eds. D.A. Hensher and K.J. Button. Elsevier Science Ltd.

34. Kröger, L. and Kickhöfer, B. (2017). Autonomous car- and ride-sharing systems: A simulation-based evaluation of various supply options for different regions. Kuhmo-Nectar 
Conference of the International Transportation Economics Association ITEA, 27-29 June 2017, Barcelona, Spain.

35. Kröger, L., Kuhnimhof, T. and Trommer, S. (2016) Modelling the impact of automated driving - private AV scenarios for Germany and the US. $44^{\text {th }}$ European Transport Conference, 5-7 October 2016, Barcelona, Spain.

36. Krueger, R., Rashidi, T. H. and Rose, J. M. (2016) Preferences for shared autonomous vehicles. Transportation Research Part C, 69, 343-355.

37. Lenz, B. and Fraedrich, E. (2016) New Mobility Concepts and Autonomous Driving: The Potential for Change. Autonomous Driving - Technical, Legal and Societal Aspects eds M. Maurer, J.C. Gerdes, B. Lenz and H. Winner, pp. 173-191. Springer.

38. Litman, T. (2014) Ready or waiting? Traffic Technology International.

39. Litman, T. (2018) Autonomous Vehicle Implementation Predictions. Implications for Transport Planning. Victoria, Canada: Victoria Transport Policy Institute, 2018.

40. Mackie, P., Wardman, M., Fowkes, A., Whelan, G., Nellthorp, J. and Bates, J. (2003) Values of Travel Time Savings in the UK. Full Report. ITS Working Papers, 561-566.

41. McFadden, D. L. (1974) Conditional Logit Analysis of Qualitative Choice Behavior. Frontiers in econometrics eds. P. Zarembka, pp. 105-141. Academic Press, New York.

42. Milakis, D., van Arem, B., and van Wee, B. (2017) Policy and society related implications of automated driving: A review of literature and directions for future research, Journal of Intelligent Transportation Systems, 21:4, 324-348, DOI: 10.1080/15472450.2017.1291351.

43. Mosquet, X., Dauner, T., Lang, N., Rüßmann, M., Mei-Pochtler, A., Agrawal, R. and Schmieg, F. (2015) Revolution in the Driver's Seat: The road to autonomous vehicles. Boston: bcg.perspectives.

44. Nieuwenhuijsen, J., Correia, G. H. d. A., Milakis, D., van Arem, B., and van Daalen, Els (2018) Towards a quantitative method to analyze the long-term innovation diffusion of automated vehicles technology using system dynamics. Transportation Research Part C: Emerging Technologies, 86, DOI:10.1016/j.trc.2017.11.016.

45. Ohnemus, M. and Perl, A. (2016) Shared Autonomous Vehicles: Catalyst of new mobility for the last mile? Built Environment, 42, 589-602.

46. Ortúzar, J. D. D. and Willumsen, L. G. (2011) Modelling transport. JohnWiley \& Sons, Ltd.

47. PWC (2015) Connected car study 2015. Racing with autonomous cars and digital innovations.

48. Revelt, D. and Train, K. (1998) Mixed Logit with Repeated Choices: Households' Choices of Appliance Efficiency Level. Review of Economics and Statistics, 80, 647-657.

49. SAE (2014) SAE International Standard J3016: Taxonomy and Definition for Terms Related to On-Road Motor Vehicle Automated Driving Systems.

50. Scheltes, A. and Correia, G. H. d. A. (2017) Exploring the use of automated vehicles as last mile connection of train trips through an agent-based simulation model: An application to Delft, Netherlands. International Journal of Transportation Science and Technology. DOI:10.1016/j.ijtst.2017.05.004.

51. Shires, J. D. and De Jong, G. C. D. (2009) An International Meta-Analysis of Values of Travel Time Savings. Evaluation and Program Plannung, 32, 315-325.

52. Steck, F., Kolarova, V., Bahamonde-Birke, F. J., Trommer, S. and Lenz, B. (2018) How Autonomous Driving May Affect the Value of Travel Time Savings for Commuting. Transport Research Record: Journal of the Transportation Research Board, in print.

53. Train, K. (2009) Mixed Logit. Discrete Choice Methods with Simulation. $2^{\text {nd }}$ edition, Cambridge University Press.

54. Trommer, S., Kolarova, V., Fraedrich, E., Kröger, L., Kickhöfer, B., Kuhnimhof, T., Lenz, B. and Phleps, P. (2016) Autonomous Driving: The Impact of Vehicle Automation on Mobility Behaviour. Institute for Mobility Research, A research facility of the BMW Group.

55. Trommer, S., Kröger, L. and Kuhnimhof, T. (2018) Potential fleet size of private autonomous vehicles in Germany and the US. Road Vehicle Automation 4 eds. Meyer, G. and Beiker, S., pp 247-256. Springer International Publishing AG.

56. Wadud, Z., Mackenzie, D. and Leiby, P. (2016) Help or hindrance? The travel, energy and 
carbon impacts of highly automated vehicles. Transportation Research Part A, 86, 1-18.

57. Winter, K., Cats, O., Martens, K. and Van Arem, B. (2017) A Stated Choice Experiment on Mode Choice in an Era of Free-Floating Carsharing and Shared Autonomous Vehicles. $96^{\text {th }}$ Annual Meeting of the Transportation Research Board, 8-12 January 2017, Washington, D.C..

58. Yap, M. D., Correia, G. H. d. A. and Van Arem, B. (2016) Preferences of travellers for using automated vehicles as last mile public transport of multimodal train trips. Transportation Research Part A, 94, 1-16.

59. Walker, J. L., Ben-Akiva, M., and Bolduc, D. (2007). Identification of parameters in normal error component logit-mixture (NECLM) models. Journal of Applied Econometrics 22(6), 1095-1125. 


\section{Appendix}

Selected scenes from the videos used in the survey to introduce the concept of autonomous driving
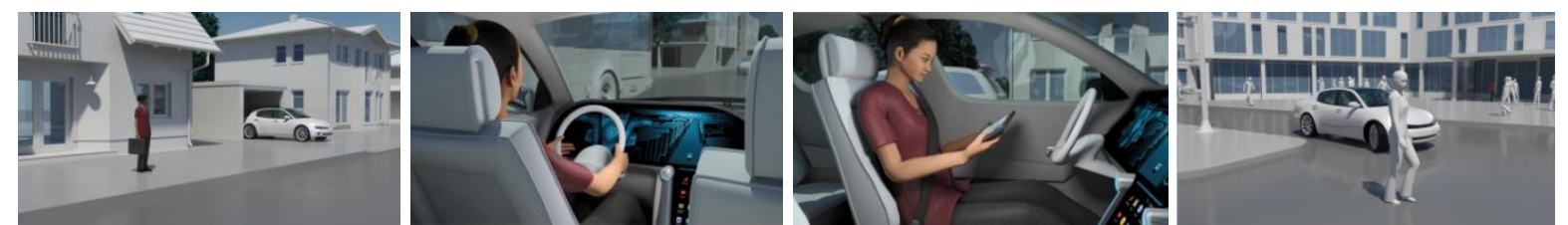

Figure 1: Video "privately owned autonomous vehicle (AV)"
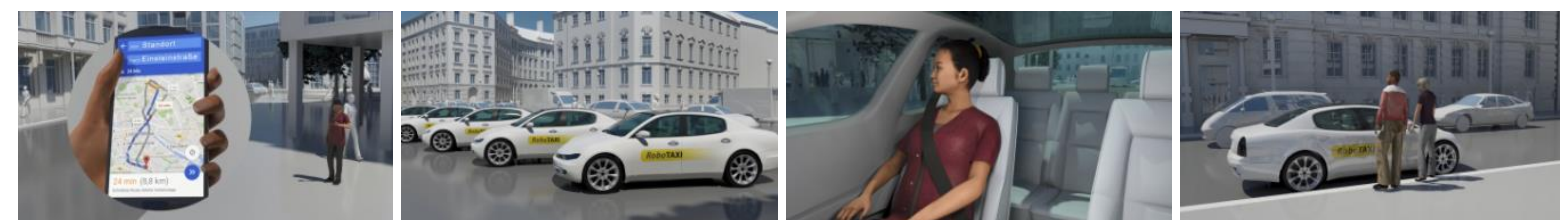

Figure 2: Video "shared autonomous vehicle (SAV)" 